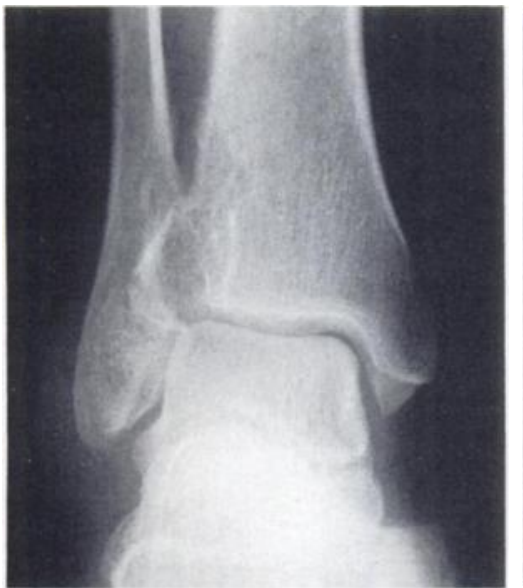

Fig. 1

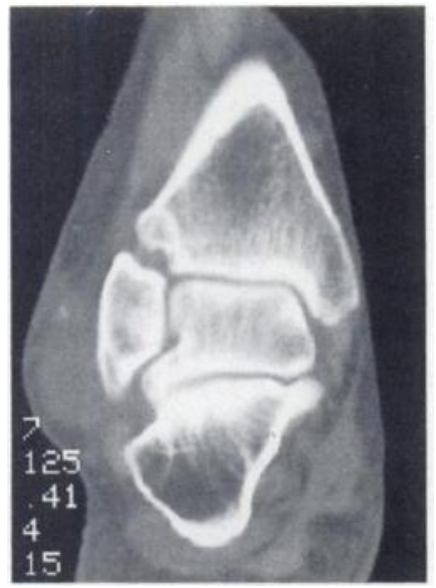

Fig. 2

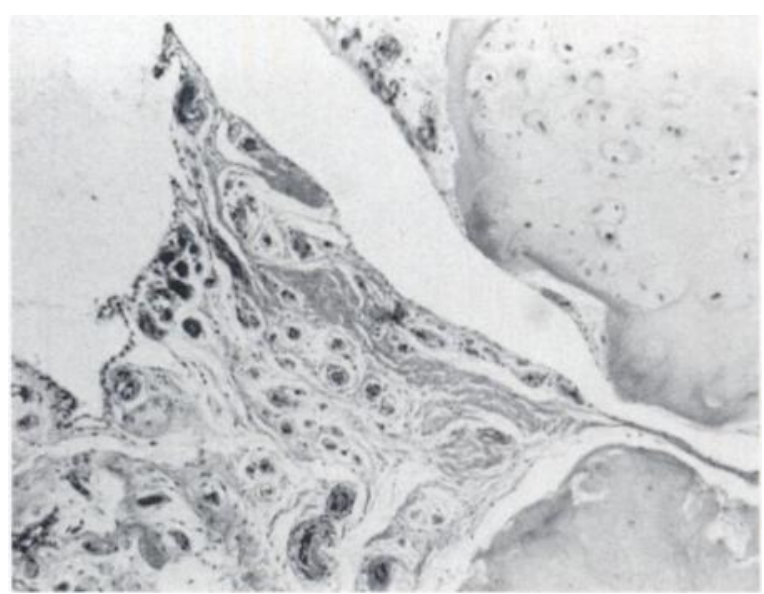

Fig. 3 present as soft-tissue masses; they may be painful and progressively enlarge. Radiography may show some calcification, but bony erosion is rare (Sim et al 1977). The lesion can be clearly defined by CT.

Extra-articular synovial chondromatosis has a benign clinical course (Dahlin and Salvador 1974), but in unusual locations it may be misdiagnosed as a soft-tissue chondrosarcoma. Factors which may cause confusion include extension of the mass into adjacent bone and evidence of chondrocytic activity with some enlarged nuclei. The diagnosis is made by the synovial origin of the cartilaginous proliferation. Sim et al (1977) emphasised the importance of recognising the synovial origin of these lesions. Local excision is usually effective; accurate histological diagnosis can avoid radical surgery.

No benefits in any form have been received or will be received from a commercial party related directly or indirectly to the subject of this article.

\section{REFERENCES}

Dahlin DC, Salvador AH. Cartilaginous tumors of the soft tissues of the hands and feet. Mayo Clin Proc 1974;49:721-6.

Sim FH, Dahlin DC, Ivins JC. Extra-articular synovial chondromatosis. J Bone Joint Surg [Am] 1977;59-A:492-5.

\title{
CORACOACROMIAL PINS TO AUGMENT EXTERNAL FIXATION OF THE UPPER HUMERUS
}

\author{
HEMANT PATANKAR, VIJAY KAKATKAR, CHANDRAKANT SHAH, VIKAS AGASHE
}

In the upper humerus, some fractures and nonunions lack enough proximal bone stock to allow sound anchorage of external fixation pins and this may lead to failure. We have devised a method of augmenting proximal fixation by the

H. Patankar, MD, MS Orth, Consultant Orthopaedic Surgeon

Patankar's Hand and Limb Reconstruction Clinic, 204 Garodia Market, Plot 8-A, D.K. Sandu Marg, next to Hotel Malhaar, Chembur, Bombay 400 071, Maharashtra, India.

V. Kakatkar, MD, MS Orth, Consultant Orthopaedic Surgeon

Aashirwad Hospital, Shyamlal Gupta Marg, Tilakwadi, Nashik 422002, Maharashtra, India.

C. Shah, MD, MS Orth, Consultant Orthopaedic Surgeon Vikas Nursing Home, Rajawadi, Ghatkoper (East), Bombay 400077 , Maharashtra, India.

V. Agashe, MD, MS Orth, Consultant Orthopaedic Surgeon Dr Agashe's Nursing Home, Bail Bazar Road, Kurla (West), Bombay 400 070, Maharashtra, India.

Correspondence to Dr H. Patankar.

(1)1995 British Editorial Society of Bone and Joint Surgery

0301-620X/95/4R37 \$2.00

$J$ Bone Joint Surg [Br] 1995;77-B:660-1.

Received 18 May 1994; Accepted 13 July 1994 use of two single half-pins introduced into the coracoid and the acromion.

Operative technique. Depending on the size and age of the patient, either a $2.0 \mathrm{~mm}$ or a $2.5 \mathrm{~mm}$ diameter half-pin is introduced percutaneously and slid along the medial side of the coracoid process to penetrate its base. It is then advanced by 1.5 to $2.0 \mathrm{~cm}$ to engage both cortices of the coracoid process. Another half-pin of the same diameter is introduced in the coronal plane through the acromion process into the scapular spine. This is advanced within the bone for about 5 to $6 \mathrm{~cm}$.

The two pins are nearly at right angles to each other. A rod of either $2.5 \mathrm{~mm}$ or $4.0 \mathrm{~mm}$ diameter is then contoured to the shape of the shoulder and the two pins are connected to it with clamps. This assembly forms the main proximal anchorage for a humeral external fixator (Fig. 1), and additional stability for the fixator is achieved by an anterior rod between the arch and the distal humeral pins.

Patients and results. We have treated four patients by this method who have been followed up for over two years. Illustrative case. A 35-year-old man presented with a com- 
minuted fracture of the upper humerus with a split humeral head dislocated anteriorly (Fig. 2a). Through a deltopectoral approach the head was fixed and reduced. The comminuted upper humeral shaft was bypassed and half-pins were introduced into the coracoid, acromion and distal humerus. External fixation (Fig. 2b) was retained until union at six weeks. The patient has an excellent painless range of active glenohumeral motion at 2.5 years' follow-up (Fig. 2c).

Our other cases included a six-year-old boy with infected nonunion of the upper humerus, which required bone grafting. He had an excellent result at three years.

We have had no complications of this fixation, such as fracture of the coracoid or acromion processes or neurovascular injury. The introduction of these pins is technically demanding; open insertion of the pins was necessary in one patient because post-traumatic swelling made accurate palpation of either process difficult.

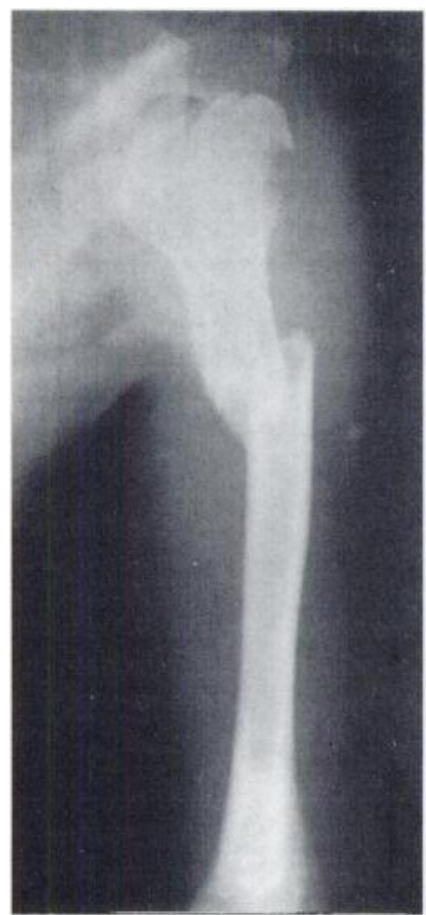

Fig. 2a

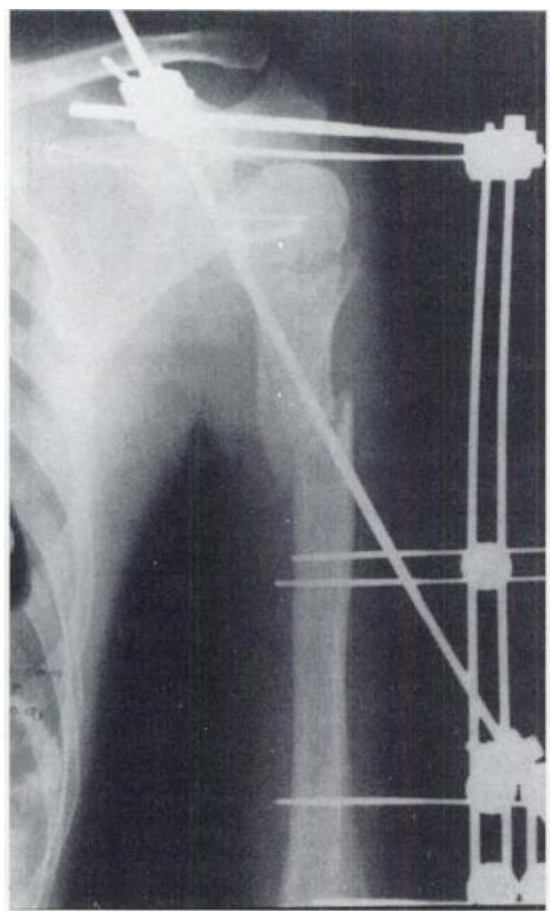

Fig. 2b

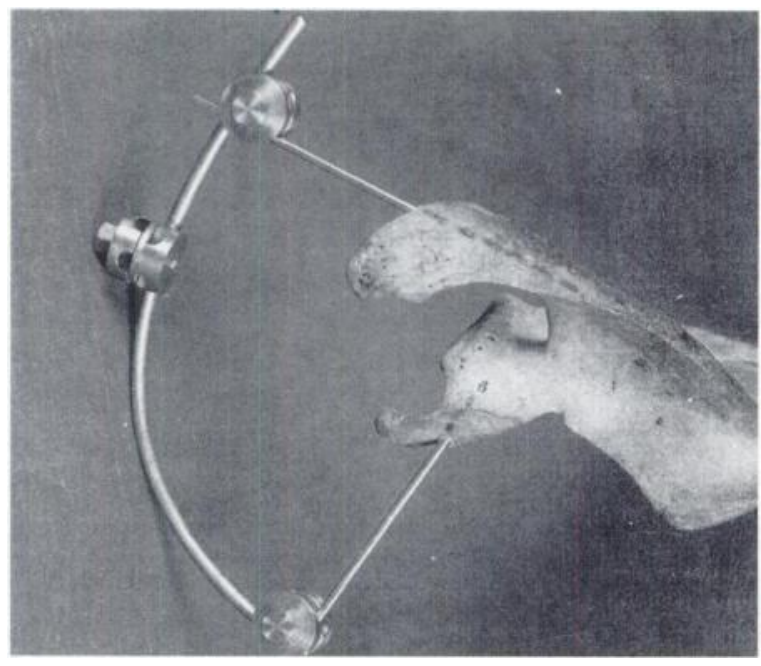

Fig. 1
Discussion. The use of half-pins placed in the clavicle or the scapular spine has previously been described (Jones 1981; Burny 1985; Brooks and Carvell 1989; Kocialkowski and Wallace 1991) but the principal technical difficulty is adequate fixation in the scapula (Mears 1979). Connecting the two half-pins at right angles to each other achieves mutual complementary fixation in the scapula, providing sound anchorage for a humeral external fixator. This alternative is especially useful when the upper humeral fragment offers poor or insecure fixation.

The authors would like to thank Professor Benjamin Joseph, Kasturba Medical College, Manipal, India for valuable comments and suggestions.
No benefits in any form have been received or will be received from a commercial party related directly or indirectly to the subject of this article.

\section{REFERENCES}

Brooks CH, Carvell JE. External fixation for fracture-dislocations of the proximal humerus. J Bone Joint Surg /Br] 1989;71-B:864-5.

Burny F. Principles of external fixation in the upper extremity. In: European Forum for Orthopaedic Science, eds. Osteosynthesis of fractures: old problems - new solutions. Oslo: European Forum for Orthopaedic Science, 1985: 103-71.

Jones RE. External fixation in open fractures. AAOS Instructional Course Lectures 1981;30:169-70.

Kocialkowski A, Wallace WA. Shoulder arthrodesis using an external fixator. J Bone Joint Surg [Br] 1991:73-B:180-1.

Mears DC. The use of external fixation in arthrodesis. In: Brooker AF Jr, Edwards CC, eds. External fuxation: the current state of the art. Baltimore: Williams \& Williams Co, 1979:241-276 